\title{
Estimation of rolling bearing life with damage curve approach
}

\author{
H. Mehdigholi, Ph. D. \\ H. Mirzaei Rafsanjani, Ph. D. \\ Behzad, Mehdi, Prof. \\ Sharif University of Technology
}

\begin{abstract}
The ability to determine the bearing life time is one of the main purposes in maintenance of rotating machineries. Because of reliability, cost and productivity, the bearing life time prognostic is important. In this paper, a stiffness-based prognostic model for bearing systems is discussed. According to presumed model of bearing and fundamental of damage mechanics, damage curve approach is used to relate stiffness of vibratory system and bearing running life. Furthermore, using the relation between acceleration amplitude at natural frequency and stiffness, final relation between acceleration amplitude at natural frequency and running life time according to damage curve approach can be established and the final running time is predicted. Experiments have been performed on self alignment bearing under failures on inner race and outer race to calibrate and to validate the proposed model. The comparison between model-calculated data and experimental results indicates that this model can be used effectively to predict the failure lifetime and the remaining life of a bearing system.
\end{abstract}

Keywords: Rolling bearing, Prognostic, Damage mechanics, Damage curve approach

\section{INTRODUCTION}

Nowadays, rotating machineries are widely used in mechanical equipments and different industries. The failure of a rolling element of bearing is one of the primary causes of breakdown in rotating machineries. Consequently, development of reliable techniques for the prediction of rotating element failure is more important to facilitate preventive maintenance.

The ability to determine the bearing life time is one of the main purposes in maintenance and condition monitoring of rotating machineries. If remaining life time of bearing be predicted then reliability of bearing will be improved and cost of maintenance will be reduced, so bearing life time prognostics is one of key points of condition monitoring of rotating machineries.

Maintenance of bearing can be categorized in two main group of diagnostic and prognostic. Currently, there are three methods for bearing diagnostic. These methods are vibration analysis $[1,2,3]$, statistical study $[4,5]$ and neural network $[6,7]$. The researches in the field of diagnostic of failures of bearings are focused on determination of failures of bearing and do not predict the running life of bearing.

Diagnostic do not estimate the bearing life while prognostic is focused on prediction of bearing life time. The studies of prognostic of remaining life of bearing is categorized in two approaches: Direct approach of fracture mechanics $[8,9,10]$, and indirect approach which is a statistical analysis of vibration signals [11].

The primary researches to estimate the remaining life of bearing was carried out in 90 decay. Li et al., 1999, used the vibration analysis and fracture mechanic to produce a recursive algorithm to predict the remaining life of bearing. These research shows that fracture mechanics can be useful to predict the bearing life. Qiu et al., 2002, used damage mechanics to predict the bearing life. In this research, three approaches of damage mechanics [Linear Damage Rule (LDR), Damage Curve Approach (DCA) and Double Linear Damage Rule (DLDR)] for trend the variation of acceleration amplitude on natural frequency of system were compared. However, the deterministic formula for estimation of remaining life of bearing did not explain. Due to previous studies in the fields of diagnostic and prognostic of bearing remaining life, this is obvious that most of researches are focused on diagnostic of defects of bearing and prognostic of bearing life time is a new branch in the field of condition monitoring and maintenance of bearings.

As a result, there is still a lack of reliable prognostic methods to predict the remaining life of berating bearing. Reliable and physically meaningful estimation of bearing life under various operating conditions remains a challenging and important aspect for maintenance optimization and catastrophe avoidance. In this paper, a stiffness-based prognostics model for a bearing system based on vibration response analysis and 
damage mechanics is developed. The effectiveness of the model has been studied by comparison between estimated life due to model and real running life of experiment, and accuracy of the model is also investigated.

\section{BEARING DYNAMIC MODEL}

A bearing system can be introduced with a self-excitation dynamic system. In this system, two types of loads exist. One type is external loads which affect bearing because of working situation and the other loads are due to defect of bearing such as surface defects, unbalancing, etc. According to the studies of Qiu et al., 2002, bearing system can be simplified as single-dof systems as shown is figure 1 .

In this model, the stiffness and damping of system have two parts: undamaged part and damage part. Undamaged part is the part of bearing which is remain safe during test running life and damage part is the part of bearing which is finally cause bearing break down. According to the fracture mechanics, high cycle fatigue is the main reason of bearing failure and during bearing life the two phase of crack (initiation and propagation) are happened. Damage part of bearing in this model is the presumed crack which finally leads to failure and its stiffness reduced during the working life. The total stiffness and total damping of bearing system is summation of stiffness and damping of damaged part and undamaged part, respectively, $=\mathrm{K}_{\mathrm{u}}+\mathrm{K}_{\mathrm{d}} \& \mathrm{C}=\mathrm{C}_{\mathrm{u}}+\mathrm{C}_{\mathrm{d}}$. In this equation $\mathrm{u}$ denotes undamaged part and denotes damaged part.

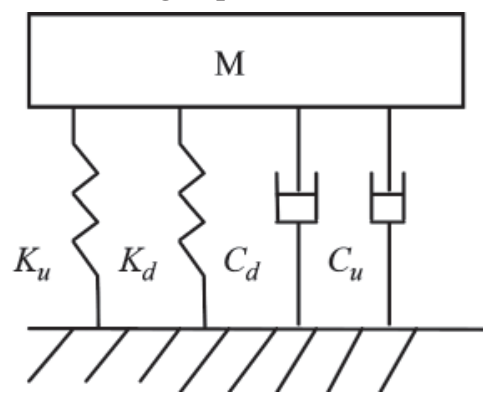

Fig. 1. The dynamic model of bearing system

Because of rotating nature of bearings the forces which are affected on bearing systems are periodic, and we call them $F(t)$. Expanding $\mathrm{F}(\mathrm{t})$ by Fourier transform, the acceleration response of system can be obtained as:

$$
\ddot{\mathrm{x}}=\sum_{\mathrm{i}} \frac{-\Omega_{\mathrm{i}}^{2} \mathrm{~F}_{\mathrm{i}} \sin \left(\Omega_{\mathrm{i}} \mathrm{t}+\alpha_{\mathrm{i}}\right)}{\sqrt{\left(\mathrm{K}-\mathrm{M} \Omega_{\mathrm{i}}^{2}\right)^{2}+\left(\mathrm{C} \Omega_{\mathrm{i}}\right)^{2}}}
$$

where:

$\Omega_{i} \quad-$ the frequency of the ith harmonic excitation $\mathrm{F}_{\mathrm{i}}, \mathrm{a}_{\mathrm{i}} \quad$ - the phase angle between $\mathrm{F}_{\mathrm{i}}$ and $\mathrm{x}$.

The amplitude of acceleration response at the natural frequency is:

$$
A_{n}=\frac{\omega_{n} F_{n}}{C}
$$

Presume proportional damping for system, $\mathrm{C}=\mathrm{aM}+\mathrm{bK}$ and considering the nature of presumed system, such as no mass enters and no mass comes out of system and the mass of system is constant, then $\mathrm{a}=0$. Consequently, damping of system is only a proportion of the system stiffness. With this presumption, equation (2) can be written as:

$$
A_{n}=\frac{c}{\sqrt{K}}
$$

where:

$c=F_{n} /(b \sqrt{M})-a$ parameter which is depend on characteristics of system.

\section{DAMAGE MECHANICS MODEL OF BEARING}

Under the definition of the reference volume element (RVE) in damage mechanics of material[12], and previous studies in this field (Qiu et al., 2002), a damage factor can be generally defined as:

$$
\mathrm{D}=\mathrm{d}\left(1-\frac{\mathrm{K}_{\mathrm{d}}}{\mathrm{K}_{\mathrm{d} 0}}\right)
$$

Where $\mathrm{d}$ is scaling factor $\left[\mathrm{d}=\mathrm{K}_{\mathrm{d} 0} /\left(\mathrm{K}_{\mathrm{d} 0}-\mathrm{K}_{\mathrm{df}}\right)\right.$ and $\mathrm{K}_{\mathrm{d}}$ is the stiffness of damage part which is reduce during the working life of bearing and initial and final value of it are $\mathrm{K}_{\mathrm{d} 0}$ and $\mathrm{K}_{\mathrm{df}}$, respectively. Based on damage mechanics, Damage curve approach can be used to relate the running life of bearing with damage factor as below

$$
\mathrm{D}=\left(\frac{\mathrm{N}}{\mathrm{N}_{\mathrm{f}}}\right)^{\mathrm{q}}
$$

where:

$\mathrm{N}$ - the running cycles,

$\mathrm{N}_{\mathrm{f}}-$ the failure lifetime in cycles,

$q^{\mathrm{f}}$ - a material and structure-dependent factor.

From equations (4) and (5), it can be shown that:

$$
\frac{\mathrm{K}_{\mathrm{d}}}{\mathrm{K}_{\mathrm{d} 0}}=1-\frac{1}{\mathrm{~d}}\left(\frac{\mathrm{N}}{\mathrm{N}_{\mathrm{f}}}\right)^{\mathrm{q}}
$$

On the other hand, the equation (3) can be written as below:

$$
\left(\frac{A_{0}}{A_{d}}\right)^{2}=\frac{c_{0}}{c_{d}}\left(\frac{K_{d}+K_{u}}{K_{d 0}+K_{u}}\right)
$$

Where $A_{d}$ and $A_{0}$ are the amplitudes of acceleration response at the natural frequency under damaged and initial conditions, respectively, and $\mathrm{c}_{\mathrm{d}}$ and $\mathrm{c}_{0}$ stand for coefficient $\mathrm{c}$ in equation (3) under damaged and initial conditions, respectively. Combination of equations (6) and (7), the final equation for estimation of the failure life is obtained as below:

$$
\begin{gathered}
\left(\frac{\mathrm{A}_{0}}{\mathrm{~A}_{\mathrm{d}}}\right)^{2}=\frac{\mathrm{c}_{0}}{\mathrm{c}_{\mathrm{d}}}\left(1-\left(\frac{\mathrm{K}_{\mathrm{d} 0}}{\mathrm{~d}\left(\mathrm{~K}_{\mathrm{d} 0}+\mathrm{K}_{\mathrm{u}}\right)}\right)\left(\frac{\mathrm{N}}{\mathrm{N}_{\mathrm{f}}}\right)^{\mathrm{q}}\right)= \\
=\alpha\left(1-\beta\left(\frac{\mathrm{N}}{\mathrm{N}_{\mathrm{f}}}\right)^{\mathrm{q}}\right)
\end{gathered}
$$

Where á, â and $\mathrm{q}$ are the coefficients depending on the operating condition, materials and structure of the system. Subscript d denotes the damaged condition, subscript 0 denotes the initial condition and subscript $\mathrm{f}$ denotes the final life time of bearing. For bearings, the failure time represents the time when the vibration signals tend to be infinite. In equation (8), $\hat{a}$ and $\mathrm{q}$ are constant for each bearing then with substitution $\mathrm{N}_{\mathrm{fe}}=\frac{\mathrm{N}_{\mathrm{f}}}{\sqrt[q]{\beta}}$, equation (8) can be written as below: 


$$
\left(\frac{\mathrm{A}_{0}}{\mathrm{~A}_{\mathrm{d}}}\right)^{2}=\alpha\left(1-\left(\frac{\mathrm{N}}{\mathrm{N}_{\mathrm{fe}}}\right)^{\mathrm{q}}\right)
$$

It is obvious that if vibration signal tends to be infinite then $\mathrm{N}$ will tend to $\mathrm{N}_{\mathrm{fe}}$. According to equation (9), obviously if unknown parameters, á and q be determined, and amplitude of acceleration response at any time of useful life of bearing be measured, then the lifetime of bearing system can be calculated during running life of bearing. To determine the unknown parameters, Recursive Least Square (RLS) parameter estimation algorithm can be used. Following, an experimental test rig is designed to validate the theoretical equation. Using RLS algorithm and experimental data, first the unknown parameters are identified and then accuracy of estimated life of bearing is investigates.

\section{EXPERIMENTAL TEST RIG}

For prognosis bearing life time an experiment test rig is used. The experimental test rig has two parts, electrical and mechanical parts. The electrical part is data acquisition system which is used to acquire the bearing vibration signals. The mechanical part of experimental test rig is shown in Fig. 2. Two supporting bearings, shaft, electromotor and main bearing test are segments of mechanical part of test rig. The shaft was driven by an electromotor with a speed controller.

Supporting bearings are self-alignment spherical roller bearing 22311EXK. These bearings can tolerate the fatigue stresses during fatigue test of bearing and would not fail during the experiment. The main bearing which is studied is a self-alignment ball bearing 1206C3. Defects on inner race and defects on outer race are main defects of this type of bearing, so both of these defects are studied. The operating conditions of the experiment are: shaft speed $1500 \mathrm{rpm}$ and radial load is equal to $9 \mathrm{kN}$.

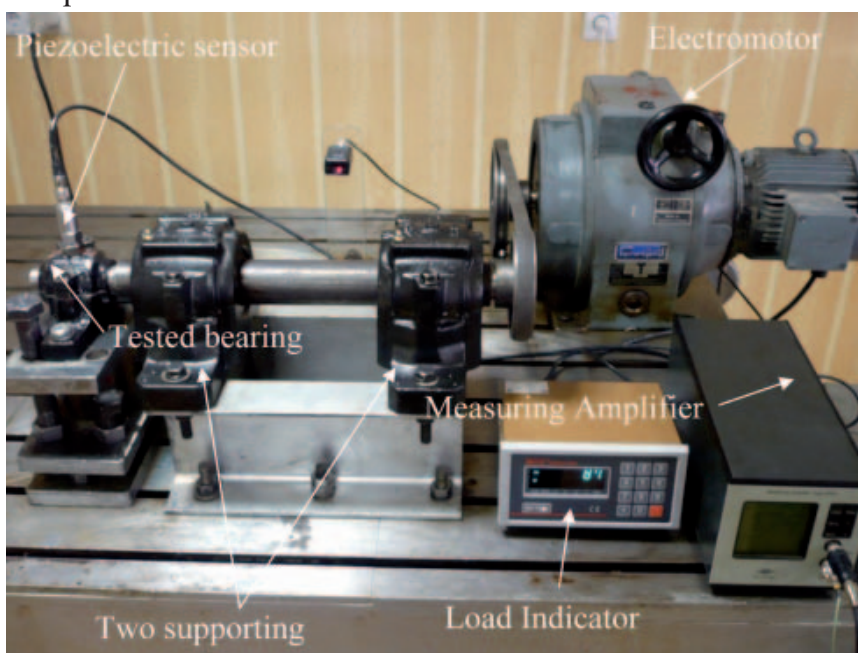

Fig. 2. Experiment test rig

The radial load which is applied to the tested bearing is measured by a load-cell (the load-cell in connected to load indicator which shown the value of load). The manufacturer of Load-cell and load indicator is Bongshin Company, load-cell model is DBBP and load indicator model is BS-7220. In Fig. 3 the loading configuration is shown. As shown in this figure, the loading configuration consists of a lower metal plate (thickness $=20 \mathrm{~mm}$ ), upper metal plate (thickness $=20 \mathrm{~mm}$ ), load-cell, 4 machine bolts (M24) and tested bearing housing. In Fig. 3 this parts are shown.

According to Fig. 4, by screwing the nut of 4 machine bolts the lower plate goes down and consequently the load-cell which is placed between two plates will be tensioned. The tension force leads to a radial force on bearing by bearing housing. In Fig. 4 the radial force is shown. The vibration signal will be measured by piezoelectric sensor. The manufacturer of sensor is ENDEVCO Company and the model of sensor is $2235 \mathrm{C}$. The signal amplifier is made by Brüel \& Kjær and its model is 2525. Moreover, $\mathrm{AD}$ convertor is made by ADVANTECH and its model is USB4711. In this experiment acceleration of tested bearing is measured.

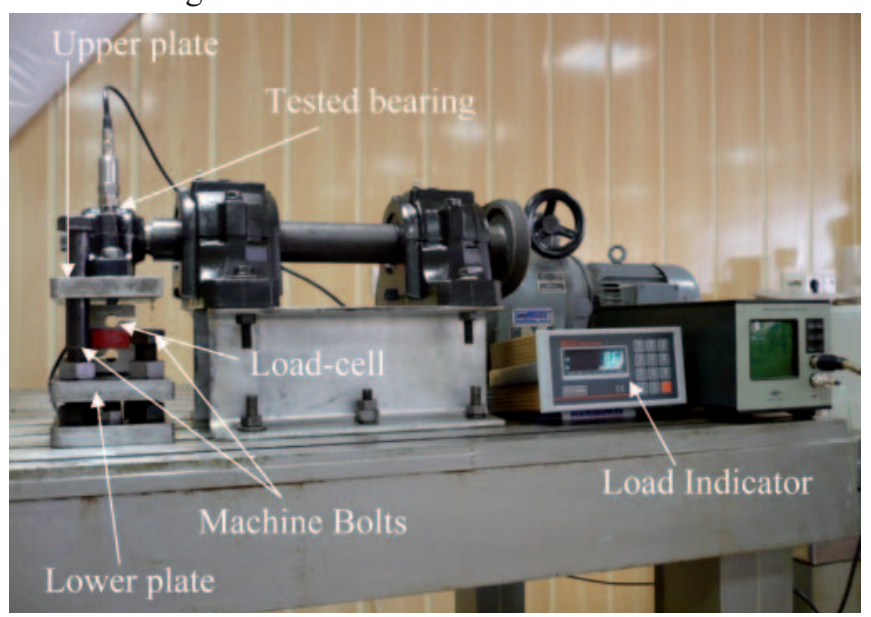

Fig. 3. Loading Configuration

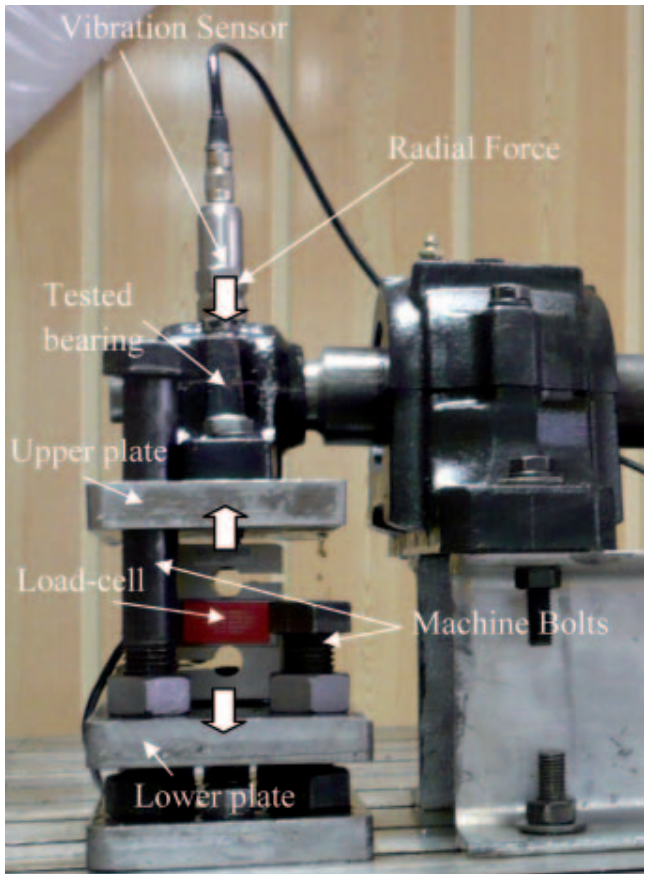

Fig. 4. Loading on tested bearing

\section{EXPERIMENTAL RESULT ANALYSIS}

As mentioned earlier, the equation for estimation of remaining life of bearing has two unknown parameters which must be defined with RLS algorithm. For this reason four primary tests are carried out to calculate these parameters. In test 1 and 2, defect is on outer race and in test 3 and 4 the defect is on inner race of the bearing. After primary tests, the unknown parameters are determined. Equation (9) is rewritten for both defects on the outer race and $t$ on the inner race, respectively, as follows:

$$
\left(\frac{\mathrm{A}_{\mathrm{n} 0}}{\mathrm{~A}_{\mathrm{nd}}}\right)^{2}=1.25\left(1-\left(\frac{\mathrm{N}}{\mathrm{N}_{\mathrm{fe}}}\right)^{6}\right)
$$




$$
\left(\frac{\mathrm{A}_{\mathrm{n} 0}}{\mathrm{~A}_{\mathrm{nd}}}\right)^{2}=0.9\left(1-\left(\frac{\mathrm{N}}{\mathrm{N}_{\mathrm{fe}}}\right)^{6}\right)
$$

Now, two tests are carried out to evaluate the precision of equations (10) and (11). In test 5, defect is on the outer race and in test 6 , defect is on the inner race. Equations (10) and (11) can be written as below:

$$
\begin{aligned}
& \mathrm{N}_{\mathrm{fe}}=\frac{\mathrm{N}}{\sqrt[6]{1-\frac{\left(\frac{\mathrm{A}_{\mathrm{n} 0}}{\mathrm{~A}_{\mathrm{nd}}}\right)^{2}}{1.25}}} \\
& \mathrm{~N}_{\mathrm{fe}}=\frac{\mathrm{N}}{\sqrt[6]{1-\frac{\left(\frac{\mathrm{A}_{\mathrm{n} 0}}{\mathrm{~A}_{\mathrm{nd}}}\right)^{2}}{0.9}}}
\end{aligned}
$$

In tests 5 and 6 , if the acceleration amplitude at natural frequency of each cycle of running life of bearing be calculated and consequently ratio of calculated amplitude acceleration to the initial amplitude $\left(\left(\mathrm{A}_{\mathrm{n} 0} / \mathrm{A}_{\mathrm{nd}}\right)^{2}\right)$ determined, then the remaining life of bearing can be estimated.

Before estimating the life of bearing in tests 5 and 6 , the rating life of bearing evaluated. The theoritical life of bearing calculated according to ISO 281:1990 by following equation:

$$
\mathrm{L}_{10}=\left(\frac{\mathrm{C}}{\mathrm{P}}\right)^{10 / 3}
$$

The $\mathrm{C}$ parameter for tested bearing is equal $15600 \mathrm{~N}$ and as mentioned previously the $\mathrm{P}$ value is equal $9000 \mathrm{~N}$; consequently, the $\mathrm{L}_{10}$ equals to $6.25^{*} 10^{6}$ revolutions. The obtained estimations of life of bearings are shown in figures (5) and (6). In figures (7) and (8), error percentage of the estimated life in tests 5 and 6 are shown.

As shown in figures (7) and (8), the final life of bearing estimated precisely during running of bearing. In test 5 , during 31 percent of last running life of bearing the error of estimated life of bearing is below 15 percent. Moreover, in test 6, during 37 percent of last running life of bearing the error of the estimated life of bearing is below 15 percent. The final estimation is more precise, error percentage of final estimation of life of test 5 is 0.36 and for test 6 the final error is 1.17 percent. Consequently, damage curve approach can be used for bearing prognostic in an online manner.

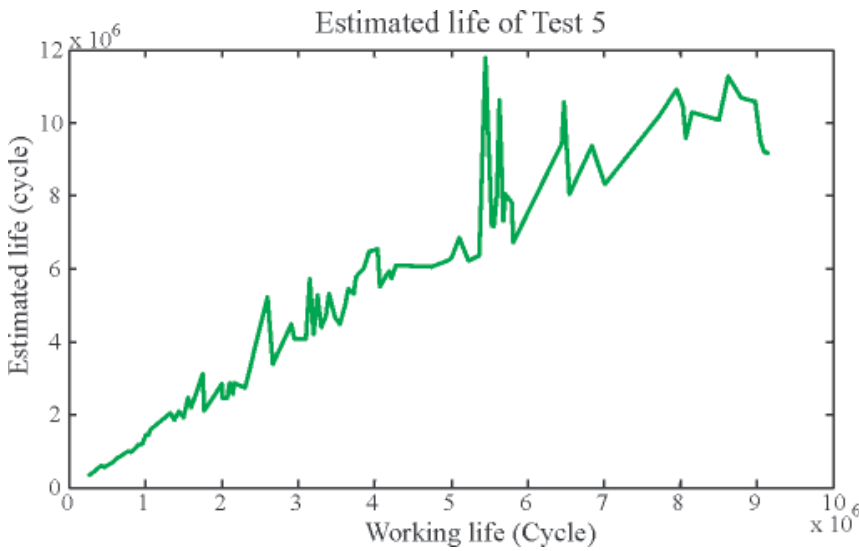

Fig. 5. Estimated life of the ball bearing in Test 5 (defect in outer race)

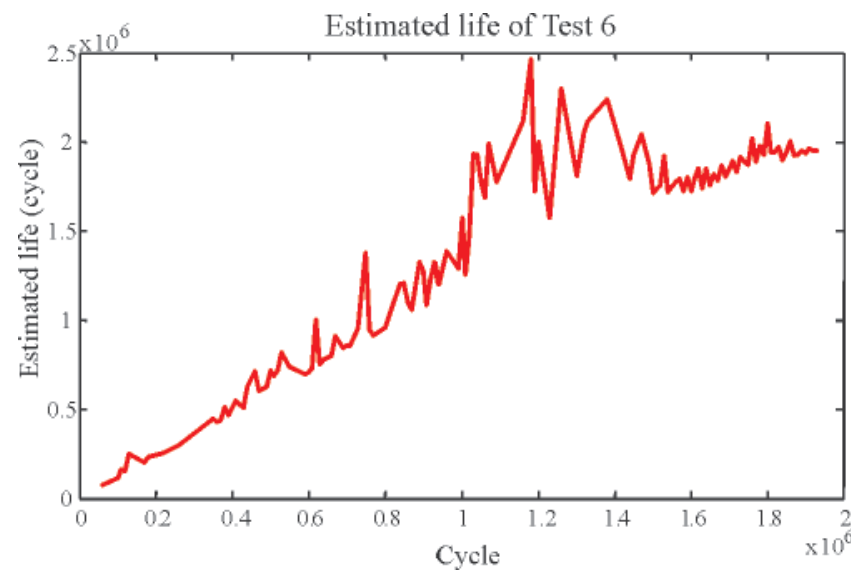

Fig. 6. Estimated life of the ball bearing in Test 6 (defect in inner race)

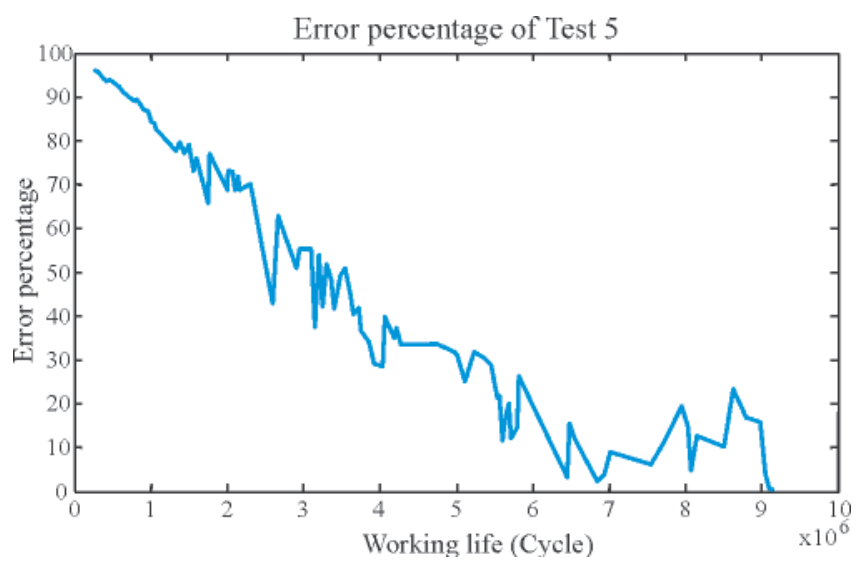

Fig. 7. Error percentage of estimated life in Test 5

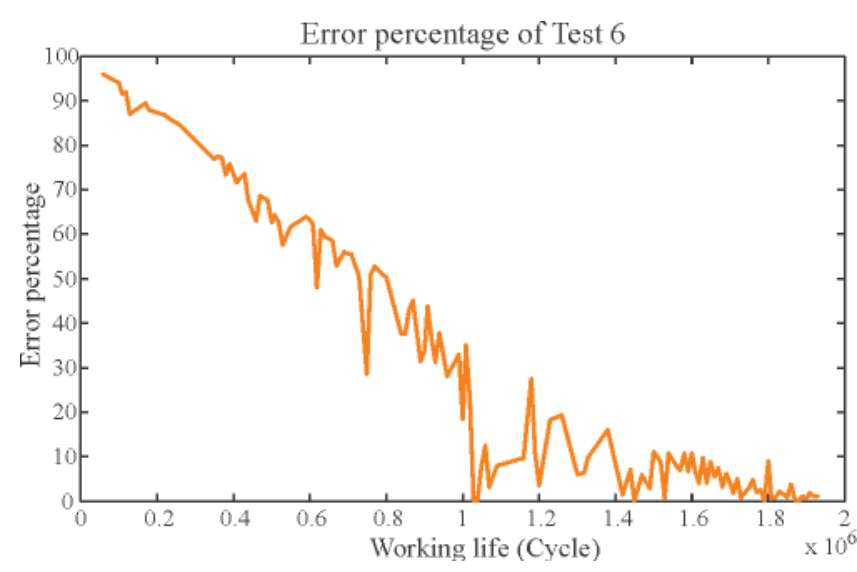

Fig. 8. Error percentage of estimated life in Test 6

\section{CONCLUSION}

This paper is used the damage curve approach to estimate the remaining life of bearing. Using damage mechanics and single-dof model for bearing system, the appropriate equation for estimation of final life of bearing is developed. Experiments are carried out to calculate the unknown parameters of theoretical equations by RLS algorithm during four primary tests. After primary tests, the unknown parameters determined. Finally, two tests are carried out to evaluate the precision of equations, and the final life of bearings estimated precisely during running of bearing (defect on inner race and defect on outer race). During last third of running life of bearing the error percent of estimated life is below $15 \%$. Consequently, the damage curve approach can be used to estimate the final 
life of bearing in online condition monitoring program. Doing this, firstly, using the DCA and RLS algorithm the predictive mathematical model must be made and then, for the other bearings we can used this mathematical model to estimate the remaining life of bearing precisely.

\section{BIBLIOGRAPHY}

1. Qui H., Lee J., Yu G.: Robust performance degradation assessment methods for enhanced rolling element bearing prognostics, Advanced Engineering Informatics, Vol. 17 No. (3-4), pp.127-140, 2003

2. Zhao Y., Zhang G., Du J., Wang G., Vachsevanos G.: Development of distributed bearing health monitoring and assessing system, $8^{\text {th }}$ International conference on control, Automation, Robotics and Vision, pp. 474-478, 2004

3. Mba D., Al-Ghamd A.M.: A comparative experimental study on the use of acoustic emission and vibration analysis for bearing defect identification and estimation of defect size, Journal of mechanical systems and signal processing, Vol. 20 No. 7, pp. 1537-1571, 2006

4. Da silva V., Fujimoto R.Y., Padovese L.R.: Rolling bearing fault diagnostic system using fuzzy logic, $10^{\text {th }}$ IEEE International Conference on Fuzzy systems, Vol 3 No. 3, pp. 816-819, 2001

5. Artes M., Del Castillo L. and Perez J.: Failure prevention and diagnosis in machine elements using cluster, proceeding of the tenth international congress on sound and vibration, pp. 11971203,2003

6. Gebraeel N., Lawley M., Liu R., Parmeshwaran V.: Residual life predictions from vibration-based degradation signals: a neural network approach, IEEE Transactions on Industrial Electronics, Vol. 51 No. 3, pp. 694-700, 2004
7. Liu T., Ordukhani F., Dipak J.: Monitoring and diagnosis of roller bearing conditions using neural networks and soft computing, International journal of knowledge-based and intelligent engineering systems, Vol. 9 No. 2, pp. 149-157, 2005

8. Li Y., Billington S., Zhang C., Kurfess T., Danyluk S., Liang S.: Adaptive prognostics for rolling element bearing condition, Journal of mechanical systems and signal processing, Vol. 13 No. 1, pp. 103-113, 1999

9. Li Y., Billington S., Zhang C., Kurfess T., Danyluk S., Liang S.: Dynamic prognostic prediction of defect propagation on rolling element bearings, Tribology Transactions, Vol. 42 No. 2, pp. 385-392, 1999

10.Qiu J., Seth B. B., Liang S., Zhang C.: Damage mechanics approach for bearing lifetime prognostics, Journal of mechanical systems and signal processing, Vol. 16 No. 5, pp. 817-829, 2002

11.Li Y., Kurfess T., Liang S.: Stochastic prognostics for rolling element bearings, Journal of mechanical systems and signal processing, Vol. 14 No. 5, pp. 747-762, 2000

12.Lemaitre J., Desmorat R.: Engineering Damage Mechanics, Springer-verlag, Berlin, 2005.

\section{CONTACT WITH THE AUTHORS}

H. Mehdigholi, Ph. D.

H. Mirzaei Rafsanjani, Ph. D.

Behzad, Mehdi, Prof.

Depatment of Mechanical Engineering,

Sharif University of Technology 11155-9567, Azadi Avenue, Tehran, IRAN

email:m_behzad@sharif.edu 